\title{
Second HSC researcher sends anonymous 'Olivieri' note
}

Barely has the surprise subsided from the revelation that a respected physician scientist at the Hospital for Sick Children (HSC) in Toronto has been sending hate mail to colleagues (Nature Med. 6, 364; 2000) than this journal has discovered that another senior researcher has become embroiled in the saga.

Sergio Grinstein, a professor in the Division of Cell Biology at the HSC Research Institute and the Department of Bio- Deferipronc (1.1) has been approved by the FiDA. chemistry at the University of Toronto, has $\mathrm{HSC}$ just completed its most successful fund rasing carnpaign cver admitted sending an Dr. B. Gallic is leaving HSC anonymous note (see The Board of Trustecs, the heads of Research, Pediastics and the $\mathrm{CFO}$ of $\mathrm{H}$ box) to Michele BrillEdwards, an expert in All's well that cnds well drug development and

Canadian drug regulatory law, expressing his views on controversial trials of the drug deferiprone, conducted at the HSC by Nancy Olivieri. Brill-Edwards finds the note "intimidating" and has reported Grinstein's activities to David Naylor, the dean of the Faculty of Medicine at the University of Toronto.

After being contracted in 1995 by Apotex, the Canadian pharmaceutical company that manufactures deferiprone, to test its efficacy as an iron chelator in $\beta$ thalassemia patients, Olivieri published evidence that the drug is ineffective with prolonged use and has the potential to cause liver fibrosis (N. Engl. J. Med. 332, $918 ; 1995)$. The issue divided the HSC community when Olivieri went public with claims that the hospital administration would not support her (Nature Med. 4, 1095; 1998 and 5, 7 and 1223; 1999).

Because of her experience as the assistant medical director at the Bureau of Human Prescription Drugs at the Health Protection Branch, Ottawa, the Canadian equivalent of the US Food and Drug Administration (FDA), Brill-Edwards is assisting Olivieri in pursuing her concerns regarding deferiprone. This includes mounting a challenge to the European approval of the drug and to a request for approval in Canada.

Brill-Edwards received the anonymous note in July 1999 shortly after attending a regulatory meeting on the safety and efficacy of deferiprone. Although she has never met Grinstein face-to-face, she was sent a signed letter from him in October 1998 in response to her article a month earlier in the Ontario newspaper The Globe \& Mail, which called for the HSC adminis- tration to admit its failings and resign. It was this communication from Grinstein that provided the DNA corroboration for the anonymous note.

In an email correspondence to Nature Medicine, Grinstein wrote that the note "stated that the drug had been approved for patient use and that people that [Brill-Edwards] had demanded resign from our Hospital were still here, while others that were involved in the controversy were no longer here." However, BrillEdwards pointed out to Nature Medicine that the note is wrong on two counts: the FDA has not approved deferiprone, and Olivieri has not left HSC.

Grinstein is the first recipient of the University of Toronto Pitblado Chair in Cell Biology, worth CAN\$2 million (US\$1.4 million). He has been a Howard Hughes Medical Institute investigator since 1991, and he has received a Medical Research Council of Canada Scientist Award and the Ayerst Award of the Canadian Biochemical Society. Thus, it remains a mystery why such an established scientist would involve himself in a research issue with which he has no direct connection by taunting a physician for questioning the safety of a drug.

Both Grinstein and his wife, Amira Klip - a professor in the Department of Pediatrics, where Gideon Koren worked until his recent suspension for sending hate mail to Olivieri and her colleague Peter Durie-are known to be uncomfortable with the negative publicity the affair has brought to the hospital. They resigned from the committee of Canada's equivalent of the Nobel committee, the Gairdner Foundation, in 1998 because the committee's chair supported Olivieri's stance. And in his 1998 signed letter to Brill-Edwards, Grinstein wrote that she has "...cast a shadow over the hospital..." and urged her to redress "...the damage you may have done to the Hospital and its community of scientists and administrators."

It is unclear what, if any, action will be taken against Grinstein. When contacted, Dean Naylor's office would say nothing more than the issue is an internal one. And at the time Nature Medicine went to press, neither the HSC nor the university would comment on the future status of Koren.

Karen Birmingham, London

\section{Sacked Spanish oncologists win reprieve}

Scientists in one of Spain's leading cancer research institutes have been given a second chance to prove their worth. Despite being told by the board of directors of the Barcelona-based Oncology Research Institute (IRO) that, because of minimal output and a lack of research grants-deficits pinpointed by an external panel-they had three months to leave the institute, IRO's research director, Josep M. Borrás, has given eight researchers a further year to improve before the panel reevaluates their perfor-

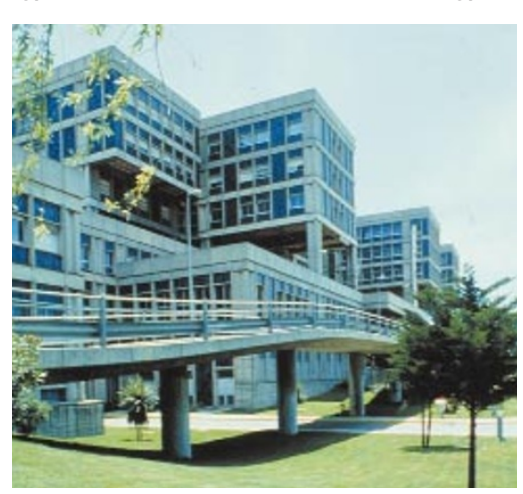
Barcelona's IRO mance. Established in 1992 at the request of the Department of Health of the Catalonian government, the IRO is a private, non-profit center employing 30 scientists, funded through various public and private institutions with an annual budget of US\$ 6.3 million.

The panel comprised two Spanish and two foreign cancer experts: Carlos Martínez-Alonso, head of Immunology and Oncology at the National Center of Biotechnology, Madrid, and Carlos López-Otín, head of Biochemistry and Molecular Biology, University of Oviedo; and Nick Lemoine of London's Imperial Cancer Molecular Oncology Unit and Jose Costa, deputy director of Yale Comprehensive Cancer Center.

They evaluated IRO's cancer research programs in February at the request of the board of directors, which was facing a financial loss of US\$500,000 in the center's budget. They assessed infrastructure and research activities as well as grants and publications of all research staff 